\title{
Under the radar: mitigating enigmatic ecological impacts
}

\author{
Keren G. Raiter ${ }^{1}$, Hugh P. Possingham ${ }^{2,3}$, Suzanne M. Prober ${ }^{4}$, and Richard J Hobbs ${ }^{1}$ \\ ${ }^{1}$ School of Plant Biology, University of Western Australia, 35 Stirling Hwy Crawley, Perth, WA, 6009 Australia \\ ${ }^{2}$ School of Biological Sciences, University of Queensland St Lucia, Brisbane, Qld, 4072 Australia \\ ${ }^{3}$ Imperial College London, Department of Life Sciences, Silwood Park, Ascot, SL5 7PY, UK \\ ${ }^{4}$ CSIRO Ecosystem Sciences, Private Bag 5, Wembley Perth, WA, 6913, Australia
}

Corresponding author: Keren Raiter, Department of Ecology, Evolution and Behavior, Hebrew University of Jerusalem, Givat Ram, Jerusalem, Israel. Email: keren.raiter@mail.huji.ac.il / keren.raiter@me.com

Citation for this article: Raiter, K.G., Possingham, H.P., Prober, S.M., Hobbs, R.J., 2014. Under the radar: mitigating enigmatic ecological impacts. Trends in Ecology \& Evolution 29, 635-644.

http://dx.doi.org/10.1016/j.tree.2014.09.003

(C) 2018 Review paper. Accepted author manuscript. This manuscript version is made available under the CCBY-NC_ND 4.0 licence https://creativecommons.org/licenses/by-nc-nd/4.0/

\section{Highlights}

- There are ecological impacts that are overlooked by standard impact evaluations

- These 'enigmatic' impacts can be cumulative, offsite, cryptic, or secondary

- Enigmatic impacts can act synergistically and are hard to detect and mitigate

- Potential solutions include strategic assessments and insurance schemes

\begin{abstract}
Identifying the deleterious ecological effects of developments, such as roads, mining and urban expansion, is essential for informing development decisions and identifying appropriate mitigation actions. However, there are many types of ecological impacts that slip 'under the radar' of conventional impact evaluations and undermine the potential for successful impact mitigation (including offsets). These 'enigmatic' impacts include those that are small but act cumulatively; those outside of the area directly considered in the evaluation; those not detectable with the methods, paradigms, or spatiotemporal scales used to detect them; those facilitated, but not directly caused, by development; and synergistic impact interactions. Here, we propose a framework for conceptualising enigmatic impacts and discuss ways to address them.
\end{abstract}

\section{Keywords}

Cumulative impacts; offsite impacts; cryptic impacts; secondary impacts; ecological impact evaluations; synergistic impacts. 


\section{The problem of enigmatic ecological impacts}

There is increasing recognition of the need to find ways to reduce the environmental impact of human development (e.g., [1-5]). This has led to a proliferation of approaches to evaluate, manage, mitigate, and offset the ecological impacts of developments. Evaluations of ecological impact, such as environmental impact assessments, biodiversity offset calculations, and conservation or land-use plans, are generally intended to account for the full range of foreseeable ecological impacts of proposed developments. However, despite the popularity of impact evaluations (see Glossary) and some substantial improvements over time, their effectiveness remains questionable [6].

In particular, impact evaluations tend to reduce complex impacts of human activity to simple, user-friendly metrics to streamline integration of economic and environmental concerns in decision making [7]. They are usually limited in scope to impacts on a predetermined subset of environmental values [4,8]. Impact evaluations are also limited by the knowledge and tools available for identifying impacts, the skills, interests, and motivations of the people conducting, approving, and auditing evaluations, and political dynamics [9-11]. Furthermore, data are often lacking for uncommon and localised species. Although some ecological impacts are simple and immediately apparent, others are subtle yet potentially far-reaching. Examples of the disparity between the full extent of impacts resulting from a development, and the impacts that have been accounted, are mounting [8,12-18]. Accounting for enigmatic impacts is not the only challenge inherent in mitigating development impacts (e.g., $[3,10,19]$ ), but addressing it is crucial: oversights in accounting for impacts undermine the ability of mitigation strategies to achieve their objectives (e.g., [12,18]).

Here, we provide a framework for conceptualising what we refer to as 'enigmatic' ecological impacts: impacts that are easily and often overlooked in impact evaluations. This framework can inform decisions regarding planning objectives, acceptable developments, offset requirements, and regional environmental mitigation strategies. We also explore ways in which the challenges of mitigating these impacts may be met.

\section{Glossary}

Ecological impact: the effects or consequences of a current or proposed action on ecosystems, processes, and ecological values and services; that is, the difference between what would happen with the action and what would happen without it [68].

Enigmatic impact: any one of a large range of ecological impacts that is not systematically accounted for in impact evaluations. We define four categories of enigmatic impact: (i) cumulative impacts: the combined effects of individually acceptable or negligible impacts that become significant at regional scales or over longer temporal scales; (ii) offsite impacts: impacts that occur away from the immediate locality of the disturbance or study area and may permeate far into apparently undisturbed areas; (iii) cryptic impacts: impacts that escape detection using existing methods, resources or technology, under existing scientific paradigms, within assessment time frames, or at the spatial and temporal scales used in the evaluation; and (iv) secondary impacts: impacts that are not directly caused by the development in question, but are facilitated by it.

Impact evaluation: any process, policy, or document that includes an evaluation of ecological impacts of development for the purposes of informing decisions or plans, or otherwise mitigating those impacts. This includes, but is not limited to, environmental impact statements and assessments, strategic assessments, applications for clearing permits or similar, works or project approvals, biodiversity offset or biobanking strategies and calculations, and conservation or land-use plans that include sustainable environmental management or biodiversity conservation (or similar) in their objectives. 


\section{Four categories of enigmatic impact}

Our framework identifies four categories of impact that are often overlooked or inadequately addressed in impact evaluations: (i) cumulative; (ii) offsite; (iii) cryptic; and (iv) secondary impacts. Interactions between multiple impacts may also be overlooked. These categories, named after the reasons for which the impacts are excluded from impact evaluations, act as a checklist for scoping the various 'enigmatic' impacts that could result from a development or series of developments. As such, the categories are not mutually exclusive: an impact may be overlooked for multiple reasons.

Exactly which category an impact belongs to, depends on the environmental, social, legislative, scientific, and technological context in which they occur, as illustrated by examples throughout this paper. Some will 'slip under the radar' in certain contexts but not in others. The first and fourth categories are adopted from existing literature and policies (e.g., [6,20]), and the second and third categories are reformulated from concepts elsewhere (e.g., $[12,21,22])$ : the four categories have not previously been synthesised in a single paper.

\section{Cumulative impacts: death by a thousand cuts}

'Cumulative impacts' refer to the sum of individual impacts that alone are considered negligible but accumulate over space and/or time and are so numerous that they are significant when considered in totality $[23,24]$. A common example of cumulative impacts is many small instances of habitat loss. Individual areas cleared for development, such as housing, drill pads, or roads, may be small but in sum could be unacceptable (Box 1). This concept was originally coined in economics as the 'tyranny of small decisions' [25] or 'death by a thousand cuts' [13].

Cumulative impacts are often overlooked because impact evaluations are often limited by laws that focus exclusively on project-by-project evaluations or impacts deemed to be 'significant', and/or 'reasonably foreseeable' $[3,4,23,24]$. The emerging fields of strategic and cumulative impact assessments attempt to address these issues, but in their present form are ineffectual or not applied widely $[3,23]$.

Two concerns regarding cumulative impacts is that they can push natural systems over ecological thresholds and their consequences may not be merely additive [5]. Nonlinear relations (such as between remnant habitat area and species richness), feedback mechanisms (such as degraded habitat being less resilient to climate change), space-time lags, and critical tipping points mean that the accumulation of numerous small impacts can be catastrophic $[5,23,26]$. For example, Florida Bay changed abruptly from a clear-water system with seagrasses and manatees to a 'dead' system with murky water dominated by plankton blooms. The change was unexpected but was probably a threshold response to long-term pollution from septic systems for a long period prior [27].

Offsite impacts: out of 'site', out of mind

Offsite impacts are those impacts that are difficult to account for in impact evaluations because they are outside the immediate location of the disturbance (the development footprint). Some offsite impacts are considered in impact evaluations (often as so-called 'indirect' impacts) but there are countless impacts that are not included because they are offsite or outside the designated project area or relevant jurisdiction.

Offsite impacts include effects that may occur at great distances from the development such as air, water, light or noise pollution; or contamination of ecosystems with dust, salt, excess nutrients, or other toxins. They also include alterations to habitat quality away from the disturbance footprint or survey area, such as changed microclimates, altered foraging potential and susceptibility to predation near edges, barriers to wildlife movement and water flow, and changes in animal behaviour with flow-on effects for ecosystems [26,28]. Such changes have been identified even when disturbances are as minor as quiet, nonconsumptive recreation, which is a land use typically thought to be compatible with biodiversity protection [29]. 


\section{Box 1. Cumulative and offsite impacts of oil sands development in Canada}

Oil-sand extraction from naturally occurring bitumen under the boreal forests of western Canada exemplifies the issue of cumulative impacts across a landscape [13]. The boreal forests of North America represent a quarter of the remaining intact forests worldwide but are becoming increasingly impacted by seismic lines and infrastructure corridors associated with the expansion of in situ energy production. The amount of vegetation cleared appears small (conventional seismic lines are 5-8 $\mathrm{m}$ wide), but the cumulative disturbance footprint of drill pads and other infrastructure is large, estimated to reach 296,000 ha over the next 40 years [13] (a). Other impacts include: depletion of freshwater resources; damage to aquatic ecosystems; acidification of land and water; contamination events; production and desalination wastes and byproducts and accidental spills; and the loss of fens and wetlands by conversion to upland landscapes [13].

However, these impacts do not end at the edge of the disturbance footprint (b). Studies have shown that the threatened woodland caribou (Figure IC) tends to avoid areas less than $1 \mathrm{~km}$ from roads and wells. Roads further fragment caribou habitat by acting as semipermeable barriers to movement $[13,69]$. This is concerning given that woodland caribou populations are declining rapidly, with an approximate halving of populations every 8 years. Projected density of artificial edges caused by oil extraction may increase from $1.8 \mathrm{~km} / \mathrm{km} 2 \mathrm{up}$ to $8.0 \mathrm{~km} / \mathrm{km} 2 \mathrm{with}$ a decline in habitat availability from $43 \%$ to $6 \%$ of the land base over the next 20 years $[13,70]$.

A suite of other species has also been found to avoid infrastructure in the boreal forests of Canada, including the yellow bellied sapsucker, lynx, marten, fisher, wolverine, boreal chickadee, brown creeper, rose-breasted grosbeak, red-breasted nuthatch, and various warblers [13]. According to Schneider and Dyer [13], 'it is the regional cumulative impact of multiple developments, not the impact at any specific site, that is of greatest concern'.
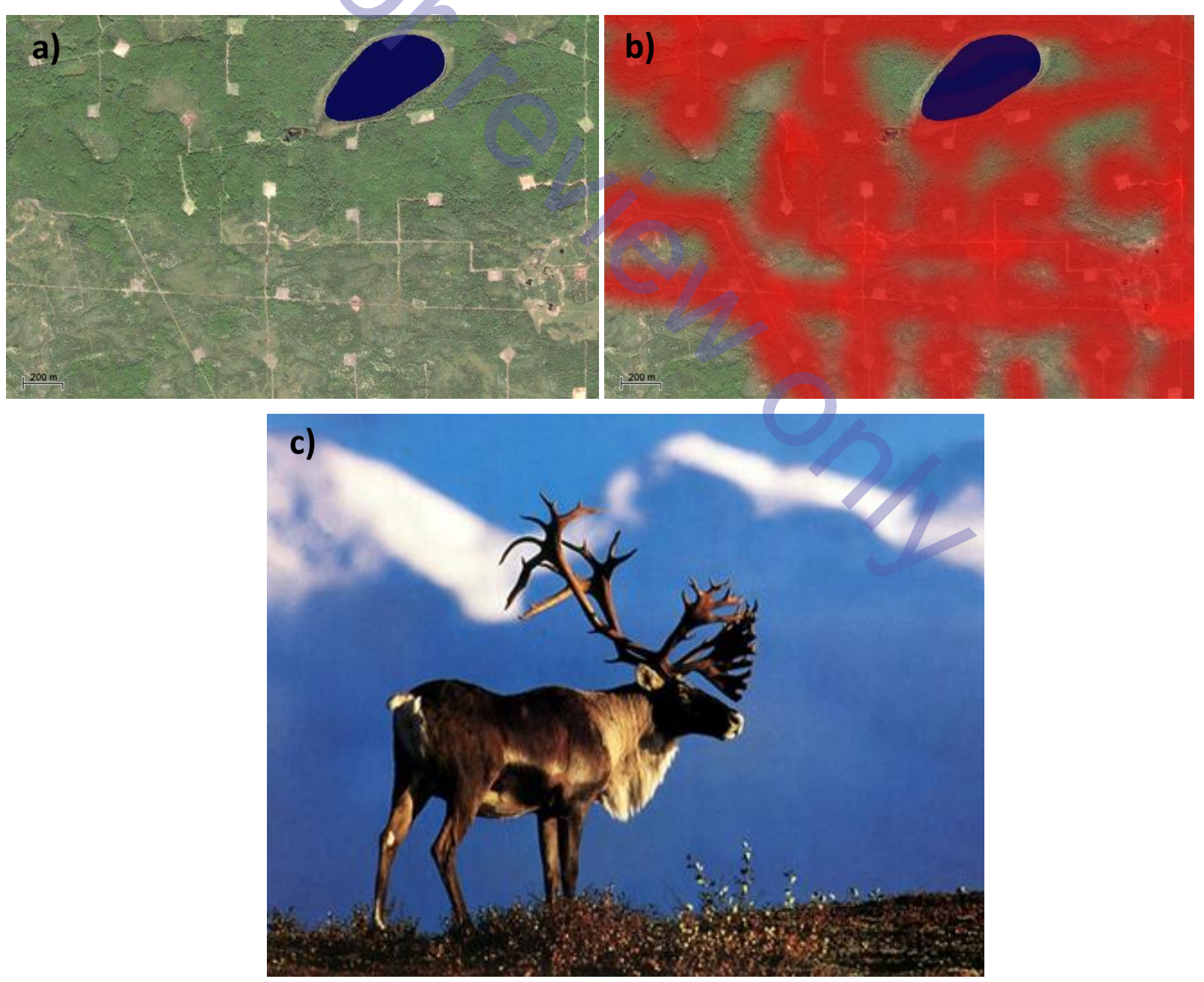

Figure Al. Enigmatic impacts from oil-sand extraction in Alberta, Canada. Satellite view of roads and well pads showing disturbance footprint (a), satellite view of roads and well pads showing wildlife avoidance zones in red (a), woodland caribou, threatened by multiple impacts of development (c). Reproduced with permission from $\mathrm{R}$. Schneider ( $a, b)$ and J. Bennett, Sierra Club Canada Foundation (c). 
The ecological impacts of hydrocarbons from the extraction, processing, transport, and use of crude oil in the Arabian Gulf exemplify offsite impacts. Hydrocarbons and other pollutants reach the waters of the Gulf by adsorbing to dust carried by wind to the marine environment or via ballast discharge, dredging, infilling, and spills $[30,31]$. Hydrocarbons can remain dissolved or suspended in water and ingested or absorbed by marine organisms and are often concentrated via food chains, with toxic and carcinogenic effects. However, these impacts are difficult to account for in impact evaluations relating to crude oil activities because of geographic and political separation between the contaminant source and sink [30,31].

More broadly, increasing flood risk to island nations and coastal areas from sea-level rise is an offsite impact of developments that produce greenhouse gases [32]. Many offsite impacts are also cryptic and are covered further below.

\section{Cryptic impacts: the arsenic in the tea}

Cryptic impacts elude detection and may be overlooked because of inherent limitations of impact evaluations, but they can be substantial. Reliable detection may be compromised by limited assessment time frames, spatial scales, statistical power, practitioner skill, technology and resources, and the practicalities of survey design [33]. Often only impacts on specific taxonomic groups, ecological communities, or environmental features are evaluated $[4,8,12,18]$.

Cryptic impacts include: noise and light pollution effects on animal communication, movement, foraging, reproductive behaviour and success, visual capabilities, community structure, and predator-prey interactions [34,35]; air pollution impacts on ovule and pollen viability [36]; fragmentation of populations and loss of genetic connectivity [28]; and unwitting disease and invasive species introductions (further examples: Box 2).

Furthermore, statistical noise frequently masks trends in ecological data to the extent that early-warning indicators fail to give sufficient warning of potential regime shifts, particularly where data are sparse [16]. Impacts of development on restricted-range endemics are often cryptic, with many species undescribed, poorly surveyed, and/or hard to find, owing to their cryptic nature [37-39]. In Western Australia, where restricted-range endemism is widespread, the Environmental Protection Authority has legislative responsibility to ensure that proposals do not threaten the viability of these species, but many impacts on such species remain unnoticed $[38,39]$.

In 2009 a mining operation in the Great Western Woodlands of south-western Australia was approved because the restricted-range ameirid copepod (i.e., a small invertebrate that inhabits underground water) found there was thought to occur elsewhere as well [38]. However, the rapid timelines imposed precluded detailed morphological or molecular determination of conspecificity. Subsequent examination found that the two populations belonged to different genera, with the initial population misidentified because of convergent morphology [38]. Consequently, the ameirid is threatened with extinction by dehydration of its habitat.

\section{Secondary impacts: Pandora's box}

Secondary impacts are not directly caused by developments but are facilitated by them, yet are generally not considered the legal responsibility of development proponents in impact evaluations. For example, secondary impacts of a hydroelectric dam include the (unintended) impacts of activities facilitated by the road network required for its construction and maintenance [40].

Indeed, secondary impacts are frequently associated with increased access to relatively undisturbed areas through such road networks. Such accessibility can attract poachers, loggers, miners, graziers, arsonists, land speculators, recreationalists, and even researchers. These uses almost inevitably result in further impacts that can extend far beyond the initial impacts of a development both in space and time, such as introductions of invasive organisms with major ramifications for ecosystems (e.g., [41]). Thus, secondary impacts are also called 'human invasions', or the 'Pandora's box effect' $[20,26]$. 


\section{Box 2. Cryptic impact examples}

Low-frequency effects on cephalopods Low-frequency underwater noise produces substantial alterations of the structures responsible for regulating balance and position in cephalopods, such as cuttlefish (Figure IA). This work has shown that the type of noise that is produced by shipping, offshore industrial construction, resource exploitation activities, and naval manoeuvres in marine environments worldwide threatens the survival of these organisms. Little is known about flow-on effects for marine ecosystems worldwide, although they may be substantial [71].

Combining native forests and exotic tree plantations for forest survey Exotic tree plantations (Figure IB) were lumped together with native forests through automatic analyses of satellite imagery by the Forest Survey of India. This resulted in misleading reports that forests in India expanded by $5 \%$ in the decade preceding 2009 , when native forests are in fact estimated to have declined by 3.5\% per year, driven primarily by forest cutting for fuel wood [12]. These rapid declines in an area that encompasses parts of three recognised biodiversity hotspots were obscured by inappropriate use and interpretation of analytical methods.

Effects of linear infrastructure on water movement and dependent vegetation Roads can have cryptic impacts on landscapes by interrupting overland flow, upon which vegetation depends (Figure 1C). The top half of Figure $1 \mathrm{C}$ shows the upslope area with annual wind grass (Aristida contorta) cover. The lower half of the image shows the effect of water starvation by the road: water from upslope is directed along the road and into creek lines and no longer flows overland [72]

Introduction of microscopic pathogens Phytophthora cinnamomi is an invasive plant pathogen almost invisible to the naked eye that is practically impossible to eradicate once introduced. This pathogen was inadvertently introduced to Australia and became widespread before it was discovered, and its impacts understood. With devastating ecological impacts globally, it is listed as one of the key threatening processes in Australia [73]. Other examples of cryptic invasions include the destructive invasion by non-native earthworms in northern America [41], and devastation caused by invasive rodents on islands, tramp ants and numerous weeds $[20,74,75]$.
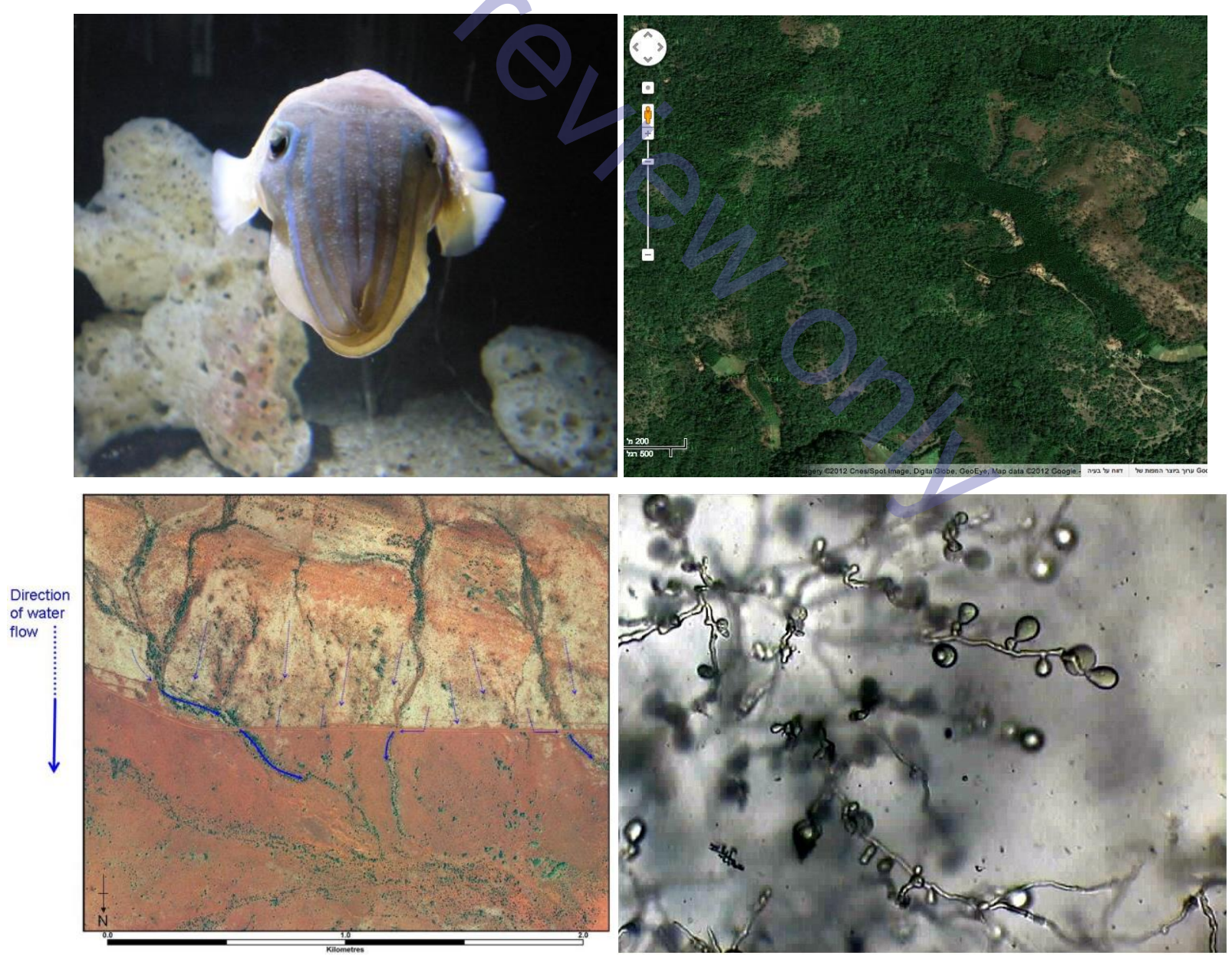

Figure I. Examples of cryptic impacts described in the literature. A cephalopod, whose survival can be threatened by industrial noise in marine environments (A), a landscape of mixed native forests and exotic plantations in India (B), a landscape in which annual wind grass has been severely impact by a road diverting overland water flow (C), and hyphal swellings of the invasive plant pathogen Phytophthora cinnamomi under a light microscope (D). Reproduced with permission from P.J. Waddell (C). 
For example, numbers of forest elephants in Central Africa have been reduced by an estimated $40 \%$ by illegal poaching for ivory. Intense poaching is a result of a combination of issues, including poverty, weak regulatory powers, and corruption, but access to elephant habitat via new roads is a demonstrated key factor determining poaching rates [42]. Despite providing much-needed economic benefits to human populations, road expansion is associated with increasing threats and local extinctions worldwide $[42,43]$.

Other examples of secondary impacts include the growing contributions of human-ignited fires, 'spontaneous colonisation', uncontrolled logging, mining, and slash-and-burn farming to deforestation in the Amazon basin, that are secondary consequences of an aggressive development strategy of the Brazilian Government $[26,44,45]$. The strategy includes US\$40 billion worth of new and upgraded highways, roads, hydro-electric reservoirs, and power-lines, and has been predicted to cause deforestation and severe degradation of up to 500000 and 2.37 million ha of forest per year respectively, with the majority of impacts above and beyond the direct impacts of the developments [44].

\section{Impact synergies}

For every pair of impacts, there are possible synergies that exacerbate environmental damage. The combined effect of the two impacts could be greater than their sum, or one phenomenon might facilitate another. For example, the synergistic effects of multiple species extinctions on ecosystem function are often greater than the additive effect of each extinction, were it to occur in isolation; also, forest fragmentation can facilitate fires $[44,46]$. It is difficult to predict interactions between different threats and stressors on multiple temporal and spatial scales, and how often they create problematic synergies $[47,48]$. Nevertheless, history shows that synergistic phenomena can have substantial ecological impacts [48], as outlined in some examples in Box 3.

\section{Box 3. Impact synergisms in space and time}

Possibly the most overlooked impacts lie beyond the full extent of individual impacts: in their interactions. Interactions may be antagonistic, additive, or synergistic; that is, the combined effect may be less than, equal to, or greater than the sum of their isolated effects, respectively [48]. Synergistic impacts may also result when one impact facilitates another. Interactions between impacts that are separated by long time periods or operate over different spatial scales are perhaps the most likely to be overlooked.

Coverdale et al. [47] investigated a latent, historical synergistic interaction between mosquito ditching that occurred on Cape Cod, Massachusetts, during the 1930s, and recent predator depletion caused by recreational fishing in developed areas. Historical construction of ditches to drain flooded mosquito breeding habitat expanded existing low marsh cord grass (Spartina alterniflora) into areas formerly dominated by high marsh, but this had little effect for decades. Recently, however, recreational fishing reduced predator abundances, such that native herbivorous crab (Sesarma reticulatum) populations exploded, causing herbivore-driven saltmarsh die-offs where low-marsh cord grass existed. The synergistic interaction between these impacts resulted in amplified die-off events despite the historical impact having been dormant for decades.

Local and global impact synergisms can also present significant challenges for impact evaluation. For example, global warming can cause direct physiological stress to seagrasses, and excessive local nutrient inputs can cause increased growth of phytoplankton and epiphytes, but the two in combination can have more deleterious impacts on seagrass meadows than their individual impacts combined [48].

Other examples of impact synergisms include interactions between habitat degradation and dominance hierarchies of reef fish that substantially alter the mechanisms that structure reef fish communities [76]. In the Amazon basin, increased fire incidence, decreased carbon storage, and changes in forest dynamics caused by logging and fragmentation of forests are amplified by changes in the climate, with potential for dangerous feedback between impacts $[26,77,78]$. 


\section{Challenges and opportunities}

Evaluating impacts is the first step to mitigating them. Some impacts are overlooked because they are difficult to detect, quantify, and attribute. In other cases, ignoring them may simply be convenient or politically expedient from a development perspective (e.g., $[12,49])$.

The difficulty of accounting for enigmatic impacts is not the only hurdle to achieving credible impact evaluations. The effectiveness of many impact evaluations can be undermined by a suite of political and economic constraints including corruption, poor governance, attitudes of governments and regulatory agencies, and persistent weaknesses in rigorous scientific input and meaningful public participation $[6,33,43,49]$.

Quantifying all the enigmatic impacts and their interactions for each development is unlikely given constraints of money and knowledge. However, given the imperatives of conservation and development, governments and proponents need to develop approaches to prevent enigmatic impacts where possible, manage the more predictable impacts, and build mechanisms to account for and mitigate the remainder in a more generic sense. Examples of such mechanisms are presented in Box 4. This process should follow the mitigation hierarchy of i) avoid, ii) minimise, iii) restore, and iv) offset; with reconsideration of approval for developments that are expected to have large enigmatic impacts $[6,50]$.

\section{Strategic and large scale evaluation and planning}

Developments in regional land use planning, cumulative and strategic assessments, strategic offsets, and integrated resource management have the greatest potential for mitigating impacts that are inadequately accounted for in project-level evaluations. Such approaches can respond proactively rather than react to developments, and provide a much needed mechanism for addressing cumulative impacts [4]. They can also help to ensure that evaluations are designed in ways that maximise their power to detect enigmatic impacts, such as allowing sufficient survey time frames, considering regional implications beyond individual projects, identifying ancillary impacts, and predicting secondary impacts $[3,4,18,44]$.

However, many such approaches are severely limited, not widely implemented and are 'under-developed' $[3,5,6,23]$. For example, in the Appalachian region of the USA the impacts of mountaintop mining are only considered for aquatic ecosystems, and severe terrestrial impacts are systematically overlooked [18]. Similarly, fewer impacts would evade consideration if evaluations were broadened from assessing impacts defined as "significant".

Trade-offs associated with expanding the scope of impact evaluations could include increased difficulty in decision-making regarding approval and prioritising mitigation actions. However, a more realistic picture of probable impacts can only serve to better inform such decisions, and numerous impacts could be grouped or weighted to ensure straightforward yet robust outcomes.

While strategic assessments can facilitate more comprehensive evaluation of enigmatic impacts, other strategic approaches can help to mitigate those impacts. For example, the benefits of offsetting numerous, small, developments may be questionable when compensatory activities are implemented separately for individual impacts, but strategic offset funds can provide consolidated sources of funding for offset activities while reducing overall costs. Such approaches would require simple rules for calculating offset requirements and could target regional environmental priorities. Importantly, they can also address cumulative impacts that are commonly too small to offset because the transaction costs of implementing the offset are higher than the cost of implementing the compensatory activity. 


\section{Box 4. Addressing enigmatic impacts in practice}

The Nature Conservancy's Development by Design: cooperative mitigation of offsite impacts

The Nature Conservancy was recently commissioned by global gold miner Barrick Gold to develop a cooperative mitigation plan for their Kanowna Belle operations in Western Australia [2,79]. The objective of the plan was to implement Barrick's corporate goal of no net loss of biodiversity. The Nature Conservancy used the science-based Development by Design mitigation planning process to develop a plan for mitigation and offsetting that included a number of elements designed to account for commonly-overlooked impacts. These comprised the inclusion of a 1-km buffer zone around mine footprints and roads in the calculation of impacts for offsetting purposes (to account for 'indirect impacts'; Figure l), a consideration of risks inherent in achieving successful offset outcomes, and a disturbance index based on the cumulative density of mapped disturbance features to inform offset options and priorities.

Environmental risk management and liability insurance for cryptic impacts If combined with laws that place responsibility for environmental impacts on development proponents, environmental liability insurance can act as a decentralised means of ensuring high regulatory compliance that could reduce oversights in addressing cryptic impacts. Insurance is an effective risk management mechanism because of its capacity to segregate and spread risk effectively, allow for the monitoring and control of behaviour, and encourage loss reduction measures [67]. Importantly, insurance schemes have a lower regulatory burden than most forms of enforcement. Although insurance has been used extensively for managing environmental risks to humans from natural disasters, it has only rarely been used to manage the risks of environmental calamities caused by human activities. Section 112(r) of the 1990 US Clean Air Act Amendments provides one example: it offers an opportunity to utilise insurance coupled with third-party inspections to encourage firms to reduce their risks of pollution events from accidents and disasters [67]. At present, impacts that are covered by insurance firms are restricted to human loss of life and injury, and environmental and social impacts remain negative externalities. There clearly is potential to include these other impacts into the insurance equation.

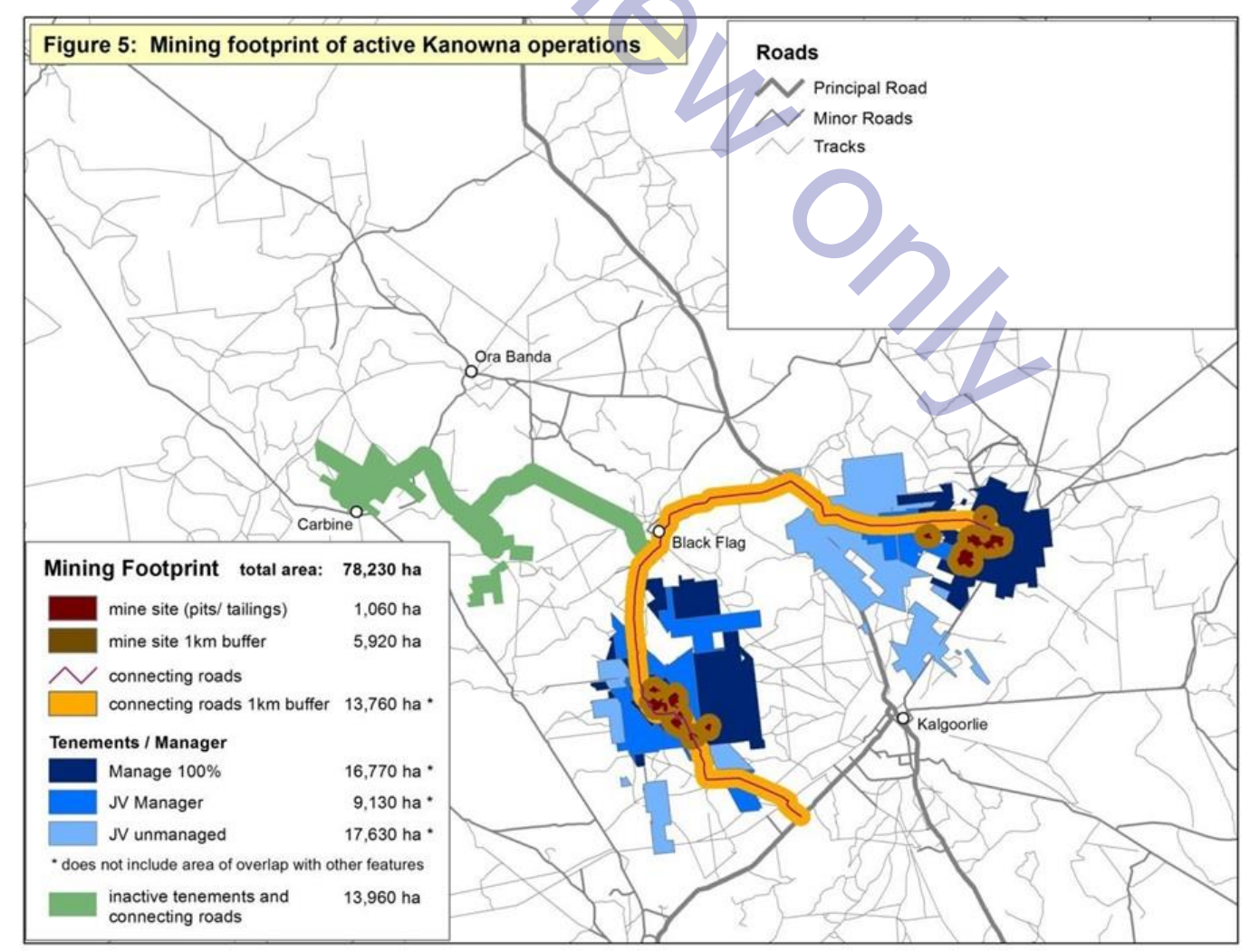

Figure I. An example of an offset calculation in which offset impacts have been taken into account with buffers around disturbed areas in a cooperative mitigation plan developed by the Nature Conservancy for Barrick Gold's Kanowna operations. Reproduced with permission from J. Kiesecker, The Nature Conservancy. 


\section{Manage, concentrate and protect}

Many enigmatic impacts could be reduced substantially by concentrating developments in areas that are already disturbed, incorporating buffer zones into land-use planning processes and impact evaluations and establishing no-development zones (or protected areas) in relatively undisturbed areas [51,52]. Roads and developments that penetrate into previously inaccessible areas are disproportionately associated with secondary [and other enigmatic] impacts, and could be avoided as a priority $[20,26]$. Limits on linear infrastructure density could be imposed in other areas. Infrastructure can be shared and consolidated where possible, and investment made into overcoming the barriers to sharing; a strategy also likely to generate cost savings [51,52]. The probable benefits of linear disturbances such as roads and firebreaks that are to be used for 'public good' purposes, such as fire management or ecological monitoring, should be assessed against possible deleterious impacts.

\section{Conserve wilderness or intactness}

Other planning policies can complement efforts to concentrate developments and establish no-development zones. Wilderness conservation policies such as the US Wilderness Act of 1964 [53] effectively prevent countless enigmatic impacts by restricting development in relatively undisturbed areas, and represent costeffective means for long-term biodiversity conservation [54]. However, wilderness is a much debated concept and is embedded in policy only in certain parts of the world [54]. Intactness indices offer a proxy for identifying areas that are less likely to be impacted by enigmatic impacts, and may provide an alternative tool for avoiding them $[55,56]$.

\section{Address historical impacts and mitigate co-occurring impacts}

Deleterious interactions between multiple impacts, including historical disturbances and global changes, need to be addressed by the societies that have benefited from these developments and by industries that further impact those ecosystems. Where little is known about managing such synergisms, developers can at least minimize their occurrence by measures such as actively rehabilitating disturbed areas, managing species invasions, and facilitating faunal movement across linear infrastructure.

\section{Access management}

Secondary impacts can be reduced by restricting public and commercial access along designated-purpose roads, addressing off-road access, and rehabilitating linear infrastructure corridors immediately after project completion. This approach may be difficult to implement in areas where the rule of law is limited and appropriate substitutes may need to be developed, such as creating alternatives to poaching or logging for income generation. Access management may also need to be balanced with community demands for infrastructure development and recreation.

\section{Enhance evaluation}

\section{Improve ethical and professional scientific practice}

A number of emerging approaches and methods have the potential to enhance evaluation and hence better inform decisions. These include generalized ecological rules of thumb and pre-cautionary approaches that can be applied without detailed assessment, and early warning indicators. Calls for addressing ongoing weaknesses in the quality of science underpinning impact evaluations are not new [33,57]. Regulatory agencies, environmental practitioners, and development proponents could improve industry standards and quality control to ensure appropriate application of effort, technology, and expertise in scoping and assessing probable impacts [38]. Rigorously elicited expert knowledge could also complement insufficient data in evaluating likely impacts [58].

Integrated use of available knowledge, precautions, decision support tools, and projections 
Some enigmatic impacts could be accounted for with estimated uncertainty buffers, and additional offset multipliers (e.g., [19]). Impact modelling and spatially explicit estimations that incorporate projected impact trends can aid in reducing uncertainty related to data deficiency and in accounting for probable future impacts, as has been done for Amazonian avifauna extinction risks [59,60,61].

Decision-support tools, such as structured decision-making and value-of-information analyses, can also aid in determining the best use of precaution and preferable courses of action in the face of uncertainty, for instance, where quarantine measures should be used, or when further research or monitoring is beneficial [62]. Such tools can also determine when resource expenditure on monitoring a cryptic threatened species, versus managing the species without monitoring, or surrendering resources to other conservation needs, is optimal [63]. This approach can be adapted to unknown threats, such as in determining when it is wiser or more cost effective to act on a conservative assumption of impact than expend resources on assessment.

\section{Research to establish baselines and early warning indicators}

Long-term ecological studies are crucial for establishing baselines and providing key insights into ecological responses to developments [64], and can be particularly helpful in accounting for cryptic impacts. Such monitoring needs to be targeted, hypothesis-driven and identify trigger points for management interventions in order to ensure its effectiveness [65]. Improvements in methods for determining early warning indicators can assist in mitigating potential regime shifts [16].

\section{Address the triple bottom line}

\section{Public participation}

Improving transparency and public engagement in planning and impact evaluations can also help to include consideration of enigmatic impacts in full-cost accounting. Lack of transparency prevents decision makers from being held publically accountable if they did not sufficiently consider likely impacts of a development, such as cryptic impacts that are overlooked by developers seeking to reduce costs or governments pursuing development agendas [4]. Collaborative governance approaches to dealing with cumulative impacts show promise in delivering improvements, although challenges remain, such as corrupt processes, and the time taken to negotiate partnership agreements and difficulty in implementing unpopular responses [66].

\section{Shift risks from society to the marketplace}

Governments could better address the risks of cryptic or low probability impacts by explicitly placing responsibility for addressing development impacts not accounted for (or inadequately accounted for) in impact evaluations, in the hands of developers during project approval. For example, if a species was unwittingly introduced into an area because of a development and became invasive, the developer would be responsible for controlling the invasion and repairing any resulting damage, even if they had abided by all regulations. Responsibility for addressing certain historical impacts or collaborating with other developers to mitigate co-occurring impacts could similarly be worked in to approval or licence conditions.

Mandatory environmental insurance schemes offer one way to enact this shift and could ensure that dedicated funds are available when further impacts emerge. Such schemes can help ensure that development decisions intrinsically take account of the risks of unaccounted impacts occurring, with the onus on the developer to better account for and prevent ecological impacts to merit lower premiums [67].

\section{Concluding remarks}

Accounting for and mitigating the full breadth of enigmatic impacts resulting from developments is ambitious but important for preventing the continued degradation of ecosystems and the biodiversity, ecological processes, and services that they support. While this may be difficult to achieve comprehensively, significant advances can be made by improving existing mechanisms and developing new ones, to account for the cumulative, offsite, cryptic, and secondary impacts of developments and their interactions. Potential 
mechanisms include improved strategic and cumulative assessments, no-development and restricted access zones, addressing historical impacts, improving professional and ethical practice and decision-making processes, and adopting environmental insurance schemes. Ultimately, it is reasonable to expect a fair accounting process whereby the beneficiaries of development are responsible for the full environmental costs of those developments; including costs that are currently borne by the broader society and future generations.

\section{Acknowledgements}

We thank B. Laurance, H. Murphy, M. Maron and an anonymous reviewer for constructive comments on previous versions of this manuscript. We gratefully acknowledge support from the Gledden Postgraduate Scholarship, The Wilderness Society, the Australian Research Council Centre of Excellence for Environmental Decisions, the National Environmental Research Program's Environmental Decisions Hub and the Great Western Woodlands Supersite.

\section{References}

1 ten Kate, K. et al. (2004) Biodiversity Offsets: Views, Experience, and the Business Case, IUCN

2 Kiesecker, J. et al. (2013) Development by Design: Cooperative Mitigation Planning for Barrick Gold's Kanowna Belle Operations in Western Australia, The Nature Conservancy

3 Morgan, R.K. (2012) Environmental impact assessment: the state of the art. Impact. Assess. Proj. Apprais. 30, 5-14

4 Alshuwaikhat, H.M. (2005) Strategic environmental assessment can help solve environmental impact assessment failures in developing countries. Environ. Impact Assess. Rev. 25, 307-317

5 Buschke, F.T. and Vanschoenwinkel, B. (2014) Mechanisms for the inclusion of cumulative impacts in conservation decision-making are sensitive to vulnerability and irreplaceability in a stochastically simulated landscape. J. Nat. Conserv. 22, 265-271

6 Pope, J. et al. (2013) Advancing the theory and practice of impact assessment: setting the research agenda. Environ. Impact Assess. Rev. 41, 1-9

7 Gasparatos, A. et al. (2008) A critical review of reductionist approaches for assessing the progress towards sustainability. Environ. Impact Assess. Rev. 28, 286-311

8 Majer, J. (2009) Saga of the short range endemic. Aust. J. Entomol. 48, 265-268

9 Bojórquez-Tapia, L.A. et al. (1998) Appraisal of environmental impacts and mitigation measures through mathematical matrices. J. Environ. Manage. 53, 91-99

10 Walker, S. et al. (2009) Why bartering biodiversity fails. Conserv. Lett. 2, 149-157

11 Atkinson, S.F. and Canter, L.W. (2011) Assessing the cumulative effects of projects using geographic information systems. Environ. Impact Asses. 31, 457-464

12 Puyravaud, J.P. et al. (2010) Cryptic loss of India's native forests. Science 329, 32-32

13 Schneider, R. and Dyer, S. (2006) Death by a thousand cuts: the impacts of in situ oil sands development on Alberta's boreal forest. In Oil Sands Fever Series (Holmes, R., ed.), Canadian Parks and Wilderness Society and The Pembina Institute

14 Edgar, G.J. et al. (2005) Species extinction in the marine environment: Tasmania as a regional example of overlooked losses in biodiversity. Conserv. Biol. 19, 1294-1300

15 Almeida-Gomes, M. et al. (2014) Underestimation of extinction threat to stream-dwelling amphibians due to lack of consideration of narrow area of occupancy. Conserv. Biol. 28, 616-619 
16 Perretti, C.T. and Munch, S.B. (2012) Regime shift indicators fail under noise levels commonly observed in ecological systems. Ecol. Appl. 22, 1772-1779

17 Roger, E. et al. (2012) Linking habitat suitability and road mortalities across geographic ranges. Landscape Ecol. 27, 1167-1181

18 Wickham, J., et al. (2013) The overlooked terrestrial impacts of mountaintop mining. Bioscience 63, 335348

19 Maron, M. et al. (2012) Faustian bargains? Restoration realities in the context of biodiversity offset policies. Biol. Conserv.155, 141-148

20 Laurance, W.F. et al. (2009) Impacts of roads and linear clearings on tropical forests. Trends Ecol. Evol. 24, 659-669

21 Osenberg, C.W. et al. (1994) Detection of environmental impacts: natural variability, effect size, and power analysis. Ecol. Appl. 4, 16-30

22 Ribaudo, M.O. (1986) Consideration of offsite impacts in targeting soil conservation programs. Land Econ. $62,402-411$

23 Therivel, R. and Ross, B. (2007) Cumulative effects assessment: does scale matter? Environ. Impact Assess. Rev. 27, 365-385

24 Canter, L. and Ross, B. (2010) State of practice of cumulative effects assessment and management: the good, the bad and the ugly. Impact. Assess. Proj. Apprais. 28, 261-268

25 Kahn, A.E. (1966) The Tyranny of small decisions: market failures, imperfections, and the limits of economics. Kyklos 19, 23-47

26 Fraser, B. (2014) Deforestation: carving up the Amazon. Nature 509, 418-419

27 Laurance, W. (2008) Climate shocks that come out of the blue. New Scientist 198, 17-17

28 Forman, R.T.T. et al. (2003) Road Ecology: Science and Solutions, Island Press

29 Reed, S.E. and Merenlender, A.M. (2008) Quiet, nonconsumptive recreation reduces protected area effectiveness. Conserv. Lett. 1, 146-154

30 Sheppard, C.R.C. (1993) Physical environment of the Gulf relevant to marine pollution: an overview. Marine Poll. Bull. 27, 3-8

31 Khan, M.A.Q. et al. (1995) Petroleum hydrocarbons in fish from the Arabian gulf. Arch. Environ. Contam. Toxicol. 29, 517-522

32 Nicholls, R.J. et al. (1999) Increasing flood risk and wetland losses due to global sea-level rise: regional and global analyses. Glob. Environ. Change 9, S69-S87

33 Treweek, J. (1996) Ecology and environmental impact assessment. J. Appl. Ecol. 33, 191-199

34 Longcore, T. and Rich, C. (2004) Ecological light pollution. Front. Ecol. Environ. 2, 191-198

35 Tyler, N. et al. (2014) Ultraviolet vision and avoidance of power lines in birds and mammals. Conserv. Biol. $28,630-632$

36 Houston, D.B. and Dochinger, L.S. (1977) Effect of ambient air pollution on cone, seed and pollen characteristics in eastern white and red pines. Environ. Pollut. 12, 1-5

37 Scheffers, B.R., et al. (2012) What we know and don't know about Earth's missing biodiversity. Trends Ecol. Evol. 27, 501-510 
38 Karanovic, T. et al. (2013) Two new subterranean ameirids (Crustacea: Copepoda: Harpacticoida) expose weaknesses in the conservation of short-range endemics threatened by mining developments in Western Australia. Invertebr. Syst. 27, 540-566

39 Harvey, M.S. (2002) Short-range endemism amongst the Australian fauna: some examples from nonmarine environments. Invertebr. Syst. 16, 555-570

40 Finer, M. and Jenkins, C.N. (2012) Proliferation of Hydroelectric Dams in the Andean Amazon and Implications for Andes-Amazon Connectivity. PLOS ONE 7, e35126

41 Loss, S.R., et al. (2012) Invasions of non-native earthworms related to population declines of groundnesting songbirds across a regional extent in northern hardwood forests of North America. Landscape Ecology 27, 683-696

42 Barnes, R. et al. (1995) A review of the status of forest elephants Loxodonta africana in central Africa. Biol. Conserv. 71, 125-132

43 Edwards, D.P. et al. (2013) Mining and the African environment. Conserv. Lett. 7, 302-311

44 Laurance, W.F. et al. (2001) The future of the Brazilian Amazon. Science 291, 438-439

45 Ahmed, S.E. et al. (2013) Temporal patterns of road network development in the Brazilian Amazon. Reg. Environ. Change. 13, 927-937

46 Valiente-Banuet, A. and Verdú, M. (2013) Human impacts on multiple ecological networks act synergistically to drive ecosystem collapse. Front. Ecol. Environ. 11, 408-413

47 Coverdale, T.C. et al. (2013) Latent impacts: the role of historical human activity in coastal habitat loss. Front. Ecol. Environ. 11, 69-74

48 Brown, C.J. et al. (2013) Managing for interactions between local and global stressors of ecosystems. PloS ONE 8, e65765

49 Lindenmayer, D.B. and Possingham, H.P. (2013) No excuse for habitat destruction. Science 340, 680-680

50 Gardner, T.A. et al. (2013) Biodiversity offsets and the challenge of achieving no net loss. Conservation Biology 27, 1254-1264

51 Kiesecker, J.M. et al. (2011) Energy by design: making mitigation work for conservation and development. In Energy Development and Wildlife Conservation in Western North America (Naugle, D.E., ed.), pp. 157181, Island Press/Center for Resource Economics

52 Tittler, R. et al. (2012) Concentrating anthropogenic disturbance to balance ecological and economic values: applications to forest management. Ecol Appl 22, 1268-1277

53 Jones-Walters, L. and Čivić, K. (2010) Wilderness and biodiversity. Journal for Nature Conservation 18, 338-339

54 Callicott, J.B. and Nelson, M.P., eds (1998) The Great New Wilderness Debate, The University of Georgia Press

55 Powers, R.P. et al. (2013) Integrating accessibility and intactness into large-area conservation planning in the Canadian boreal forest. Biological Conservation 167, 371-379

56 Scholes, R. and Biggs, R. (2005) A biodiversity intactness index. Nature 434, 45-49

57 Greig, L.A. and Duinker, P.N. (2011) A proposal for further strengthening science in environmental impact assessment in Canada. Impact Assess. Proj. Apprais. 29, 159-165

58 Martin, T.G., et al. (2012) Eliciting Expert Knowledge in Conservation Science. Conservation Biology 26, 29-38 
59 Bird, J.P. et al. (2011) Integrating spatially explicit habitat projections into extinction risk assessments: a reassessment of Amazonian avifauna incorporating projected deforestation. Diversity and Distributions $18,273-281$

60 Schneider, R.R. et al. (2003) Managing the cumulative impacts of land uses in the Western Canadian Sedimentary Basin: a modeling approach. Conserv. Ecol. 7, 8

61 Loss, S.R. et al. (2012) Direct human-caused mortality of birds: improving quantification of magnitude and assessment of population impact. Front. Ecol. Environ. 10, 357-364

62 Moore, J.L. and Runge, M.C. (2012) Combining structured decision making and value of information analyses to identify robust management strategies. Conservation Biology 26, 810-820

63 Chadès, I. et al. (2008) When to stop managing or surveying cryptic threatened species. Proceedings of the National Academy of Sciences, USA 105, 13936

64 Lindenmayer, D.B. et al. (2012) Value of long-term ecological studies. Austral Ecol 37, 745-757

65 Lindenmayer, D.B., et al. (2013) Counting the books while the library burns: why conservation monitoring programs need a plan for action. Front. Ecol. Environ. 11, 549-555

66 Eberhard, R. et al. (2013) A collaborative approach to address the cumulative impacts of mine-water discharge: Negotiating a cross-sectoral waterway partnership in the Bowen Basin, Australia. Resources Policy 38, 678-687

67 Freeman, P.K. and Kunreuther, H. (2004) Managing environmental risk through insurance. In The International Yearbook of Environmental and Resource Economics 2003/2004. A Survey of Current Issues (Folmer, H. and Tietenberg, T., eds), pp. 159-189, Edward Elgar Publishing

68 International Association for Impact Assessment (2009) What is Impact Assessment? International Association for Impact Assessment

69 Dyer, S.J. et al. (2001) Avoidance of industrial development by woodland caribou. J. Wildlife Manage. 61, 531-542

70 Hervieux, D. et al. (2013) Widespread declines in woodland caribou (Rangifer tarandus caribou) continue in Alberta. Can. J. Zool. 91, 872-882

71 André, M., et al. (2011) Low-frequency sounds induce acoustic trauma in cephalopods. Front. Ecol. Environ. 9, 489-493

72 Waddell, P. et al. (2012) A report on the Gascoyne River catchment following the 2010/11 flood events. In Resource Management Technical Report 382 Department of Agriculture and Food, Western Australia

73 Shearer, B. et al. (2004) Quantification of the susceptibility of the native flora of the south-west botanical province, Western Australia, to Phytophthora cinnamomi. Aust. J. Bot. 52, 435-443

74 Harper, G. and Carrion, V. (2011) Introduced rodents in the Galápagos: colonisation, removal and the future. In Island invasives: eradication and management. (Veitch, C., Clout, M., and Towns, D., eds) pp. 63-66, IUCN, Gland, Switzerland.

75 Commonwealth of Australia (2006) Background document for the threat abatement plan to reduce the impacts of tramp ants on biodiversity in Australia and its territories. Department of the Environment and Heritage

76 Boström-Einarsson, L.E. et al. Habitat degradation modifies the strength of interspecific competition in coral dwelling damselfishes. Ecology (in press)

77 Cochrane, M.A. and Laurance, W.F. (2008) Synergisms among fire, land use, and climate change in the Amazon. AMBIO 37, 522-527 
78 Laurance, W.F. et al Apparent environmental synergism drives the dynamics of Amazonian forest fragments. Ecology (in press)

79 Fitzsimons, J., et al. (2014) Development by Design in Western Australia: Overcoming Offset Obstacles. Land 3, 167-187 